\title{
Desenvolvimento de Conceitos: O Paradigma das Transformações
}

\author{
José Fernando Bitencourt Lomônacoㄹ, Fräulein Vidigal de Paula, \\ Cláudia Berlin de Mello e Fabiane de Amorim Almeida \\ Universidade de São Paulo
}

\begin{abstract}
RESUMO - Keil (1989) investigou se artefatos e espécies naturais permaneciam membros das mesmas categorias após transformações mudando seus aspectos característicos mais salientes. Este trabalho replica um de seus experimentos, objetivando comprovar a validade de seus resultados em nosso meio. Participaram 30 crianças, subdivididas em três grupos (6/7; 8/9 e 10/ 11 anos). Traduziu-se seis estórias, quatro referentes a espécies naturais, duas a artefatos. Estas relatavam situações em que médicos operavam espécies naturais e artefatos alterando suas propriedades comportamentais e perceptivas mais salientes e transformando-os em outras espécies, referentes à mesma categoria. A cada sujeito narrou-se as estórias e ao final de cada uma perguntava-se se ocorreu a transformação em outra espécie. Observou-se que os sujeitos avaliaram corretamente a identidade dos artefatos, mas somente com o aumento da idade os atributos definidores passaram a ser considerados para avaliação da identidade correta das espécies naturais. De maneira geral, nossos resultados confirmaram o estudo de Keil.
\end{abstract}

Palavras-chave: formação de conceitos; desenvolvimento de conceitos; visão teórica.

\section{Development of Concepts: The Transformations Paradigm}

\begin{abstract}
Keil (1989) investigated whether artifacts and natural kinds remains members of the same categories after transformations that change their most salient features. This paper replicates one of Keil's experiments with purpose to ascertain whether the results are applicable to the Brazilian culture. Participated 30 children who were assigned to three groups (6/ 7, 8/9, 10/11 years old). Six stories were translated - four about natural kinds and two about artifacts. They talked about doctors who performed operations on natural kinds and their most salient artifacts whereby properties were changed in those of the another kind. Results showed that subjects were able to correctly assess the identity of the artifacts, but the defining attributes were effective only for the older children. In general, the results give support to Keil's findings.
\end{abstract}

Key words: concept formation; conceptual development; theory view.

Em dois trabalhos anteriores [Lomônaco, Caon, Heuri, Santos \& Franco, 1996 e Lomônaco e cols., (no prelo)], foram apresentadas as quatro principais concepções teóricas que, ao longo do século XX, foram propostas para explicar o processo de formação de conceitos. O leitor interessado poderá consultá-las se desejar conhecê-las em maior profundidade. Nesta introdução teórica consideraremos de maneira suscinta as três primeiras concepções e, de uma maneira um pouco mais detalhada, a última delas - a visão teórica - uma vez que ela dá fundamento ao presente trabalho.

Embora ainda estejamos muito longe de uma definição de conceito universalmente aceita pelos psicólogos - o conceito de conceito - existe uma ampla concordância entre eles de que os conceitos constituem um determinado tipo de agrupamento cognitivo - uma representação mental - que possibilita ao organismo reduzir drasticamente a complexidade do ambiente. Se tivéssemos que responder individualmente, por exemplo, a todas as árvores com as quais entramos em contato no decorrer de nossa vida, teríamos de criar milha-

1 Endereço: Instituto de Psicologia da Universidade de São Paulo; Av. Prof. Mello Moraes, 1721; Cx. Postal 66261; CEP 05508-900; Fax (011)3813-8895; São Paulo; e-mail jfblusp@ usp.br res de representações mentais - uma para cada árvore vista e também memorizar milhares de rótulos ou nomes para cada uma de nossas representações.

Certamente (e felizmente) não é isso o que ocorre. Graças à capacidade de categorizar ou de formar conceitos, que os organismos desenvolveram ao longo de sua história filogenética, somos capazes de criar representações mentais de objetos, eventos e pessoas e, no dizer de Bruner e cols. (1967), ...responder a eles em função de sua inclusão como membros de uma classe e não como entidades particulares... (p.1). A maneira pela qual os organismos, a partir de experiências exclusivas com particulares vem a formar conceitos gerais, tem sido objeto permanente do interesse de filósofos e psicólogos (Lomônaco, 1997). No campo da psicologia, podemos assinalar quatro teorias (ou visões, como são comumente designadas) como as mais representativas desta tentativa de explicar o processo de formação de conceitos: as visões clássica, prototípica, dos exemplares e teórica.

De maneira muito suscinta, podemos dizer que a principal característica da visão clássica é a pressuposição da existência de atributos ou traços necessariamente comuns a todos os membros de uma categoria. Através da abstração desses atributos comuns, os organismos vem a formar uma representação mental que sumariza os aspectos partilhados por 
todos os subconjuntos de uma classe. É a esta representação mental que damos o nome de conceito.

Contrariamente à visão clássica, a visão prototípica pressupõe que o conceito é formado pela abstração dos atributos que ocorrem com maior frequiência entre os membros de uma categoria. Nega a existência de atributos definidores de conceitos naturais e acredita que, a partir desses atributos característicos ou mais freqüentes, o indivíduo forma uma representação mental denominada protótipo. Uma vez formado, o protótipo será utilizado como critério para decidir a inclusão ou exclusão de itens na categoria. Se o item for suficientemente similar ao protótipo ele será incluído; se não o for, será excluído.

A visão dos exemplares, por sua vez, acredita que, ao invés da formação de um protótipo, as categorias são representadas por um ou alguns exemplos individuais representativos. Assim, por exemplo, um professor que ao longo de sua vida profissional tenha entrado em contato com muitos alunos estudiosos, acabará por tomar um ou alguns deles como exemplo do "bom aluno". Uma vez selecionado um ou alguns exemplos, este(s) passará(ão) a representar o conceito de "bom aluno". Da mesma forma que na visão prototípica, novos itens serão incluídos ou excluídos da categoria em função da similaridade com exemplos da categoria previamente armazenados.

Não obstante as claras diferenças entre essas três teorias de conceito, existe um aspecto em que elas se assemelham. Qual seja, todas elas explicam a coesão conceitual com base no fator similaridade. Similaridade de atributos comuns na visão clássica; similaridade a um protótipo ou a exemplos armazenados na memória nas visões prototípica e dos exemplares, respectivamente.

Coesão conceitual diz respeito ao fator que mantém os exemplos de uma categoria unidos ou coesos. É ela que responde à pergunta: Por que temos as categorias que temos e não outras? Ou, em outras palavras, qual a "cola" que une os diferentes itens agrupados sob um mesmo conceito? Como visto, as três teorias consideradas procuram explicar o fenômeno da coesão conceitual atribuindo-o ao fator similaridade.

Todavia, como salientam Murphy e Medin (1985), a noção de similaridade é demasiadamente ampla. Assim, apelar para a similaridade na explicação do processo de formação de conceitos, pode levantar mais questões do que fornecer respostas.

Um procedimento muito simples permite-nos facilmente avaliar a procedência de tal crítica. Tome-se ao acaso dois objetos quaisquer, por exemplo, óculos e televisão. Podemos facilmente identificar um conjunto muito grande de atributos comuns a esses objetos: são invenções humanas, pesam menos de 100 quilos, não existiam na Grécia antiga, podem ser vendidos e comprados, são úteis aos homens, podem ser vistos a olho nu, são usados apenas pelos seres humanos etc. Não obstante esse grande número de similaridades entre óculos e televisão, eles não são agrupados, em nossa cultura ocidental, numa mesma categoria, mas fazem parte de categorias muito diferentes uma da outra. O que
Murphy e Medin (1985) desejam salientar com esta crítica é o fato de que, sem restrições sobre o que deve ou não ser considerado como atributos definidores de um conceito, praticamente qualquer categorização pode ser feita pelo ser humano, o que na verdade não ocorre. Em suma, a similaridade por si só não consegue explicar adequadamente a coesão conceitual.

Diante de tais limitações, vem se desenvolvendo, a partir da década de 80, uma nova abordagem a respeito da formação de conceitos, a visão teórica. A principal pressuposição desta teoria é a de que os conceitos são tipos de coisas intrinsecamente relacionais. No dizer de seu maior propugnador ...Nenhum conceito pode ser entendido sem alguma compreensão de como ele se relaciona com outros conceitos... (Keil, 1989, p.1).

O conceito, então, passa a ser visto não mais isoladamente, mas como parte de uma rede de relações da qual deriva seu significado. A esta rede de relações é atribuído o nome de "teoria". A palavra teoria aparece entre aspas uma vez que, nesta visão de conceitos, o termo refere-se comumente a relações estabelecidas pelo senso comum. Por exemplo, o conhecimento que uma criança tem a respeito de animais, o fato de saber que eles nascem, crescem e morrem, que se alimentam, que procriam filhotes da mesma espécie etc constitui sua "teoria" desse campo conceitual ou sua biologia "ingênua". Sem dúvida, também em outras áreas do conhecimento é possível identificar esta rede de relações entre conceitos, dando origem a uma "física" ingênua, a uma "psicologia" ingênua etc. Em suma, o conhecimento que as pessoas têm do mundo, quer aquele adquirido através da educação formal (e que, freqüentemente, implica na aprendizagem de teorias científicas), quer aquele adquirido de maneira informal e acidental (e que, freqüentemente difere, em maior ou menor grau, do conhecimento científico) é considerado como a teoria do sujeito a respeito de aspectos do seu mundo.

Na década de 80, Keil (1989) leva a cabo um programa de pesquisas destinado a investigar as mudanças qualitativas que se supõem ocorrer com a idade nas teorias dos sujeitos. Com tal objetivo, elaborou um engenhoso procedimento que consiste em, através de pequenas estórias narradas, identificar a natureza do conceito que o sujeito tem em mente. A peculiaridade dessas estórias consiste em, ora apresentar situações nas quais atributos característicos de um conceito estão presentes, mas o(s) atributo(s) definidor(es) está(ão) ausentes(s), ora apresentar situações em que o(s) atributo(s) definidor(es) está(ão) presente(s), mas os atributos característicos estão ausentes (ver no anexo as estórias utilizadas nesse trabalho).

Keil (1989) acredita que, com o decorrer da idade, ocorre uma mudança qualitativa no desenvolvimento dos conceitos. Tal mudança consiste num gradual afastamento das propriedades características dos exemplos de uma categoria e numa conseqüente aproximação ou atenção a suas propriedades definidoras. Keil acredita, também, que o desenvolvimento cognitivo não ocorre de maneira global e simultânea para todos os conceitos e/ou domínios conceituais, mas 
que cada conceito e/ou domínio conceitual segue um curso de desenvolvimento próprio. Neste aspecto, a visão teórica opõe-se às teorias de estágios, tais como as de Piaget, Bruner, Vygotsky etc - segundo as quais mudanças qualitativas no desenvolvimento cognitivo ocorrem simultaneamente para todos os domínios, quando o indivíduo passa de um estágio para outro.

Assim, para Vygotsky (1934/1979) a aquisição de conceitos genuínos ocorre numa sequência de três fases:

1) A primeira fase é caracterizada pela formação de imagens de um amontoado de diferentes objetos agrupados na base de alguma impressão casual, subjetiva e idiossincrática.

2) A segunda fase é denominada pensamento por complexos. Num complexo os objetos individuais isolados encontram-se reunidos no cérebro da criança não só pelas suas impressões subjetivas, mas também por relações existentes entre esses objetos (p. 87/88). Todavia, as ligações entre os seus elementos são mais de natureza concreta e factual do que abstrata e lógica, sendo essa a principal diferença entre um complexo e um conceito verdadeiro.

3) Finalmente, a última fase caracteriza-se pela utilização de princípios logicamente coerentes para o agrupamento de elementos dentro de uma categoria.

Como bem resume Keil (1989), um dos aspectos fundamentais da teoria de Vygotsky é a pressuposta natureza global da mudança conceitual. Em suas palavras: antes de um certo ponto no desenvolvimento as crianças teriam grande dificuldade em representar qualquer conceito em termos de uma definição baseada em princípios; e, depois deste ponto, elas seriam capazes de fazê-lo facilmente para a maioria dos conceitos (p.7).

Também Bruner e Piaget defendem idéias similares sobre o desenvolvimento conceitual. Qual seja, a ocorrência de mudanças ontogenéticas de natureza global no curso do desenvolvimento cognitivo que se iniciam pelo atentar para atributos concretos e facilmente perceptíveis, passa pelos atributos funcionais dos objetos e culmina com a consideração de atributos mais abstratos e verbais.

Atualmente tais idéias a respeito do desenvolvimento conceitual já não são tão unanimemente aceitas como o eram a alguns pouco anos atrás. É possível afirmar que, a partir de 1980, estudiosos do desenvolvimento cognitivo (p. ex. Carey, 1985; Murphy \& Medin, 1985; Keil, 1989) vêm apresentando objeções à idéia de mudanças globais e homogêneas no desenvolvimento de conceitos e sugerido que os conceitos se desenvolvem de forma mais específica e heterogênea segundo o domínio conceitual (p. ex. relações de parentesco, domínio da moral, acidentes geográficos, conceitos de refeições etc). Esta nova abordagem ao desenvolvimento conceitual tem sido comumente designada de especificidade de domínio. Os que a defendem acreditam que as mudanças qualitativas que ocorrem no processo de formação de conceitos podem ser totalmente explicadas supondo-se que os mesmos sistemas computacionais e representacionais são partilhados por indivíduos de todas as idades; o que se de- senvolve é a capacidade de usar esses sistemas numa amplitude cada vez maior (Keil, 1989).

A fim de testar tais suposições, Keil (1989) idealizou um conjunto de pesquisas para analisar as teorias ingênuas das crianças e suas implicações no processo de categorização. Tal conjunto pode ser classificado em três grupos: 1) pesquisas com conceitos nominais; 2) pesquisas com conceitos naturais e artefatos, utilizando-se o paradigma das descobertas e 3) pesquisas com conceitos naturais e artefatos, utilizando-se o paradigma das transformações.

Por conceitos nominais entende-se aqueles estabelecidos por convenção social. São apresentados na forma de definições simples que explicitam suas propriedades necessárias e suficientes (p. ex., sobrinho, roubo, altruísmo, aniversário etc). Artefatos consistem num subconjunto das espécies nominais referente a objetos criados pelo homem, que lhes confere intencionalmente uma função (ex.: cadeira, torno mecânico, janela, livro etc). Os conceitos naturais dizem respeito àquela espécie de coisas cuja ocorrência no mundo independe da atividade humana, coexistindo na natureza como entidades governadas por um conjunto de leis comuns a todas elas (p. ex.: ouro, orquídea, árvores, animais, oceanos, tigre etc).

Keil (1989) iniciou sua investigação pelos conceitos nominais, que se aproximam mais das definições clássicas e permitem, conseqüentemente, uma clara distinção entre os atributos característicos (que não fazem parte da definição de um conceito, mas estão freqüientemente associados à maioria dos exemplos) e os definidores (que são necessários e suficientes para incluir os exemplos na categoria).

No primeiro grupo de trabalhos, Keil (1989) pesquisou o desenvolvimento de conceitos referentes a cinco domínios conceituais, numa amostra de crianças de seis, oito e dez anos. Com tal objetivo, elaborou duas pequenas estórias para cada conceito. A primeira estória apresentava uma situação em que vários atributos característicos de um conceito eram apresentados, mas o atributo definidor estava ausente. Por exemplo, no conceito referente à avó, uma senhora idosa, bondosa e de cabelos brancos, mas que não era mãe de nenhum dos pais, era a personagem principal. Na segunda estória uma senhora jovem, esportiva, de cabelos pretos e que era mãe de um dos pais exemplificava o conceito. Depois de narrar cada estória, o(a) experimentador(a) perguntava ao sujeito se a personagem em questão (pessoas, animais, situações, artefatos etc) era ou não um exemplo do conceito. Após cada resposta do sujeito, seguia-se uma breve entrevista destinada a esclarecer pontos duvidosos e avaliar a segurança do sujeito em relação a suas respostas.

Keil (1989) verificou que, à medida que as crianças se tornam mais velhas, vão progressivamente atentando menos para os aspectos característicos e voltando-se mais para os definidores. Verificou, também, que esta mudança do característico para o definidor não ocorre ao mesmo tempo para todos os domínios conceituais; em alguns domínios (moral, por exemplo) os conceitos já estão formados, enquanto em outros (relações de parentesco, por exemplo) ainda estão em processo de formação. Keil explica tal resultado como de- 
corrência do grau de desenvolvimento das "teorias" das crianças. Em alguns domínios as "teorias" das crianças refletem adequadamente a realidade; em outros, elas se atêm a aspectos característicos / superficiais em detrimento dos definidores. Uma réplica parcial deste tipo de trabalho foi realizada em nosso meio por Lomônaco e cols. (1996), com resultados bastante similares aos de Keil.

Num segundo conjunto de trabalhos, Keil (1989) procurou investigar se a descoberta de "essências" internas ou princípios causais subjacentes alteraria as categorizações das crianças a respeito de espécies naturais e artefatos. O pesquisador levanta duas hipóteses: $1^{\mathrm{a}}$ ) se as crianças não tiverem teorias causais bem desenvolvidas a respeito das propriedades que observam nas espécies naturais, elas não darão importância à descoberta de propriedades fundamentais das espécies; $2^{\mathrm{a}}$ ) crianças que ignoram teorias relevantes deverão apresentar padrões de resposta semelhantes para artefatos e espécies naturais, uma vez que, em ambos os casos, consideram as propriedades descobertas como irrelevantes.

Com o intuito de avaliar em que medida tais descobertas afetam a categorização, Keil (1989) também se utilizou de pequenas estórias, agora referentes a pares de espécies naturais (por ex., cavalo / zebra) e de artefatos (p. ex, chave / moeda), nas quais uma entidade tinha todas as características perceptivas e comportamentais de um membro do par, mas propriedades fundamentais ou essenciais do outro. Numa dessas estórias, por exemplo, os cientistas "descobriram" que um animal que apresentava todos os aspectos exteriores de um cavalo (relinchar, usar sela, ser chamado de cavalo etc), na verdade, por dentro, era uma vaca (tinha ossos de vaca, sangue de vaca, procriava bezerros etc). Indagava-se, então, à criança o que o animal era realmente, cavalo ou vaca? No tocante a artefatos, uma das estórias narrava o derretimento de moedas para, com o metal resultante, fazer chaves. Ao final, perguntava-se à criança o que elas achavam que as coisas eram: chaves ou moedas? A amostra de sujeitos e o procedimento foram semelhantes ao do estudo dos conceitos nominais, anteriormente descrito.

Os resultados demonstraram que, no tocante às espécies naturais, as descobertas dos cientistas não influenciaram a categorização das crianças mais novas, porém afetaram significativamente as das mais velhas. Ou seja, no exemplo da estória mencionada, as crianças mais jovens insistiam em considerar esses animais como cavalos, apesar de possuírem sangue e ossos de vaca, serem filhos de vaca e terem bezerros como filhotes. Já as mais velhas afirmaram que os animais eram vacas, apesar de serem muito parecidas com cavalos. Em relação a artefatos, não houve diferenças significantes entre os grupos de idade: tanto as crianças mais jovens, quanto as mais velhas julgaram que as descobertas dos cientistas em nada alteraram a classificação dos diferentes artefatos. Assim, no exemplo considerado, todos os grupos de crianças julgaram que, embora feitos com o metal derretido de moedas, os objetos eram, de fato, chaves. Também em nosso meio Lomônaco e cols. (no prelo) replicaram parcialmente o estudo de Keil (1989), encontrando resultados bastante similares aos do trabalho original.
No terceiro conjunto de trabalhos, Keil (1989) procurou avaliar as mudanças de características acidentais para atributos essenciais através de transformações sofridas por espécies naturais e artefatos. Em suas palavras:

As descobertas não são a única maneira pela qual nossas crenças a respeito da natureza dos exemplos podem ser mudadas. Nós também podemos provocar transformações nas propriedades desses exemplos e, se as propriedades e o método de transformação forem apropriados, poderemos julgar se os exemplos tornaram-se membros de uma espécie diferente ( $\mathrm{p}$. 183).

A fim de avaliar em que medida as transformações afetam a categorização dos sujeitos, Keil (1989) desenvolveu um procedimento no qual eram descritas situações em que cientistas realizavam operações em espécies naturais e artefatos, de modo a transformar suas propriedades comportamentais e perceptivas mais salientes nas de outra espécie, porém dentro da mesma categoria geral (isto é, artefato em artefato, animal em animal).

Da mesma forma que nos trabalhos anteriores, foram elaboradas pequenas estórias narrando as situações de transformações. Após o relato das transformações que mudavam os aspectos característicos mais salientes de uma espécie nas de outra espécie contrastante, perguntava-se à criança se a espécie natural (ou artefato) continuava a mesma, ou se havia se transformado em uma outra espécie (ou artefato). Dois exemplos de estórias utilizadas ajudam a esclarecer o procedimento.

Tigre / Leão: Os cientistas pegaram um tigre como esse (mostra-se o desenho de um tigre). Eles usaram um alvejante especial para peles, removeram as listas e costuraram uma enorme juba, de tal modo que ele ficou assim (mostra-se o desenho de um leão). Depois da operação, o animal é um tigre ou um leão?

Lata de lixo / Cadeira: Cientistas pegaram uma lata de lixo como essa (mostra-se a figura de uma lata de lixo). Eles pegaram a borda de cima e a cortaram em quatro tiras, fazendo com que essas tiras ficassem retas. Então eles cortaram o fundo da lata e pregaram nelas as quatro tiras. Depois eles cortaram um retângulo da parte do lado da lata de lixo e mais duas tiras. Aí eles juntaram todas essas partes assim (mostra-se a figura de uma cadeira com braços). Depois que eles acabaram, eles ficaram com uma lata de lixo ou com uma cadeira?

Como observa Oliveira (1994), em capítulo de livro no qual descreve e analisa as diferentes teorias de conceitos, este conjunto de estudos é, num certo sentido, inverso do anterior. No paradigma das descobertas, mantém-se a aparência e alteram-se as características essenciais das entidades. Neste paradigma, a aparência é mudada, mantendo-se inalteradas as características profundas. Foram elaboradas quinze estórias, sendo sete referentes a espécies naturais e oito a artefatos. A amostra e o procedimento foram similares aos trabalhos anteriores.

Keil (1989) hipotetizou que as crianças mais jovens, cujas teorias a respeito de propriedades biológicas estão menos 
bem desenvolvidas, considerariam que as transformações mudariam uma espécie em outra. Já as crianças mais velhas não se deixariam influenciar pelas mudanças superficiais. No tocante aos artefatos, tanto as crianças mais novas quanto as mais velhas não seriam afetadas pelas transformações efetuadas.

Os resultados desses estudos foram semelhantes ao do paradigma das descobertas. Ou seja, no tocante às espécies naturais as crianças mais novas acreditavam que, após as transformações sofridas, uma espécie tinha se transformado em outra. Para as mais velhas, tais transformações em nada alteraram a natureza das entidades (o tigre continuava sendo tigre). Quanto aos artefatos, em todos os grupos de idade, os sujeitos afirmavam uma mudança de categoria após as transformações realizadas (a lata de lixo havia se transformado realmente em uma cadeira). Este último resultado, como salienta Keil (1989), possibilita contrastar os padrões de desenvolvimento desses dois tipos de conceitos.

Considerando-se que a visão teórica como explicação do processo de formação de conceitos é relativamente recente em Psicologia, ainda pouco conhecida em nosso meio, necessitando ainda de maior número de estudos para validá-la empiricamente, Lomônaco e cols. (1996, no prelo) replicaram parcialmente dois trabalhos de Keil: o referente a conceitos nominais (1996) e o relativo ao paradigma das descobertas (no prelo). Neste terceiro trabalho nosso objetivo é avaliar o desenvolvimento de conceitos, numa amostra de crianças brasileiras, utilizando-se como procedimento de investigação o paradigma das transformações. Mais especificamente, procurar-se-á verificar se, no desenvolvimento de conceitos,

a) ocorre efetivamente uma mudança de ênfase das propriedades características para as propriedades definidoras, com o aumento da idade; $\mathrm{e}$

b) se tal mudança ocorre igualmente para conceitos referentes a espécies naturais e artefatos.

\section{Método}

\section{Sujeitos}

Participaram como sujeitos 30 alunos de uma escola particular de educação infantil e de ensino fundamental da cidade de São Paulo, freqüentada predominantemente por clientela de classe média. As 30 crianças foram subdivididas em três grupos de dez sujeitos, de acordo com a faixa etária. A amostra ficou assim constituída: Grupo I - cinco meninos e cinco meninas, com idade média de seis anos; Grupo II sete meninas e três meninos, com idade média de oito anos e Grupo III - cinco meninos e cinco meninas, com idade média de dez anos.

\section{Material}

Foram utilizadas seis estórias traduzidas e adaptadas do estudo de Keil (1989), sendo quatro delas referentes a espécies naturais (cavalo/ zebra, tigre/ leão, frango/ peru, chum- bo/ ouro) e duas a artefatos (gravata/ cadarço de sapato, lata de lixo/ cadeira). Todas as estórias relatavam uma situação fictícia em que, ou atributos característicos de uma espécie eram implantados de maneira tal que, ao final do processo de transformação, o objeto ou animal viesse se assemelhar a um outro objeto ou animal, ou operações executadas sobre objetos realmente o transformavam em um outro artefato. Por exemplo, o cavalo ficaria parecido com uma zebra (ver estórias no Anexo). Foram utilizados também gravadores portáteis e fitas cassete para gravar as entrevistas feitas com as crianças).

\section{Procedimento}

A cada criança individualmente foram narradas as seis estórias. No início de cada uma delas era mostrada ao sujeito uma figura do artefato ou espécie que estava sendo transformado(a) (p. ex., cavalo). Ao final da estória, o experimentador mostrava a figura na qual o artefato ou espécie natural poderia ter se transformado (p. ex., zebra) e perguntava à criança como ela categorizava o item após a transformação. Após cada resposta, seguia-se uma breve entrevista na qual o experimentador pedia que o sujeito justificasse sua resposta.

A ordem de apresentação das estórias foi a mesma para todos os sujeitos. As entrevistas foram gravadas e, posteriormente, transcritas para análise.

\section{Resultados}

As respostas dos sujeitos foram avaliadas independentemente por três juizas, co-autoras do trabalho, que atribuíram escores de 1 a 3 , de acordo com os critérios propostos por Keil (1989), quais sejam:

a) Escore 1 - quando o sujeito baseia-se nos aspectos característicos e, assim, julga que a espécie foi realmente mudada pelas transformações superficiais;

b) Escore 2 - quando o sujeito mostra-se indeciso, vacilando entre aspectos característicos e definidores;

c) Escore 3 - quando o sujeito baseia-se nos atributos definidores e, assim, mantém a identidade da espécie apesar das transformações superficiais.

No caso dos artefatos, diferentemente das espécies naturais, foi atribuído o escore 1 quando o sujeito afirmava a identidade do objeto após a transformação e o escore 3 quando negava que o artefato continuasse o mesmo, reconhecendo que a operação efetuada transformou realmente um objeto em outro (p.ex., uma gravata em cadarço de sapato).

O grau de concordância interjuizes foi calculado através da fórmula

$$
\mathrm{GC}=\frac{\mathrm{C}}{\mathrm{C}+\mathrm{D}} \text { onde }
$$

$\mathrm{C}=$ número de concordâncias e $\mathrm{D}=$ número de discordâncias

O índice de concordância interjuizes variou de 0,80 a 1,0. Para fins de análise estatística, foram utilizadas as avaliações de um dos juízes dos pares que apresentaram os mai- 
Tabela 1. Frequiências absolutas e médias dos escores dos sujeitos em função da idade e do tipo de estória.

\begin{tabular}{lcllllll}
\hline \multirow{2}{*}{ Idade } & \multirow{2}{*}{ Escore } & \multicolumn{3}{c}{ Espécies Naturais } & \multicolumn{2}{c}{ Artefatos } \\
\cline { 2 - 8 } & & E1 & E2 & E3 & E4 & E5 & E6 \\
\hline 6 anos $n=10$ & 1 & 8 & 8 & 6 & 6 & 0 & 1 \\
& 2 & 1 & 2 & 3 & 4 & 0 & 0 \\
& 3 & 1 & 0 & 1 & 0 & 10 & 9 \\
\hline média & 1,3 & 1,2 & 1,5 & 1,4 & 3,0 & 2,8 \\
\hline anos $n=10$ & 1 & 7 & 7 & 8 & 5 & 0 & 0 \\
& 2 & 0 & 1 & 2 & 3 & 2 & 1 \\
& 3 & 3 & 2 & 0 & 2 & 8 & 9 \\
\hline 10 anos $n=10$ & 1 & 4 & 3 & 2 & 1 & 0 & 1 \\
& 2 & 0 & 1 & 2 & 0 & 0 & 0 \\
& 3 & 6 & 6 & 6 & 9 & 10 & 9 \\
\hline & média & 1,6 & 1,5 & 1,2 & 1,7 & 2,8 & 2,9 \\
\hline
\end{tabular}

Obs: $E 1$ = tigre/leão; $E 2$ = frango/peru; $E 3=$ cavalo/zebra; $E 4=$ chumbo/ ouro; $E 5=$ lixo/cadeira; $E 6=$ gravata/cadarço de sapato.

ores graus de concordância. Assim sendo, a concordância entre os juizes cujas avaliações foram utilizadas no tratamento estatístico variou do mínimo de 0,87 ao máximo de 1,0. As freqüências absolutas e a média dos escores dos sujeitos, por idade, estórias e tipos de conceito, são apresentadas na Tabela 1.

A inspeção da Tabela 1 mostra-nos que, no tocante às espécies naturais, as médias dos escores aumentam de acordo com o aumento da idade, variando de 1,2 no Grupo I (E2) a 2,8 no Grupo III (E4). O mesmo não ocorre em relação aos artefatos, cuja amplitude de variação foi de apenas 0,2 pontos (de 2,8 a 3,0), indicando que, até mesmo crianças muito novas, já desenvolveram "teorias" adequadas a respeito das conseqüências das transformações efetuadas nos artefatos.

Foram conduzidas análises estatísticas via Modelo Linear de Análise Multivariada (MANOVA), tendo a variável idade dos sujeitos como fator entre grupos e a variável tipo de estória como fator intra sujeitos. Estas análises revelaram efeitos principais significantes de idade dos sujeitos $\left(F_{[3,120]}\right.$ $=5,94 ; p<0,000)$, assim como da interação entre idade $\mathrm{e}$ três estórias referentes a espécies naturais, $\left(\mathrm{E} 1: F_{[3,30]}=2,57\right.$, $p=0,095 ; \mathrm{E} 2: F_{[3,30]}=5,39, p=0,011 ; \mathrm{E} 3: F_{[3,30]}=8,42, p=$ $\left.0,001, \mathrm{E} 4: F_{[3,30]}=2,25, p=0,000\right)$, mas não entre idade e estórias referentes a artefatos $\left(\mathrm{E} 5: F_{[3,30]}=2,25, p=0,125\right.$; E6: $\left.F_{[3,30]}=0,111, p=0,895\right)$. Na Tabela 2 são apresentados os resultados do teste Bonferroni de comparações múltiplas post hoc, para um nível de 0,05 , referentes às idades e às estórias).

As comparações intergrupos relativas às espécies naturais (as quatro primeiras estórias), não revelaram quaisquer diferenças significantes entre os grupos de 6 e 8 anos; revelaram duas diferenças entre os grupos de 8 e 10 anos e três diferenças entre os grupos de 6 e 10 anos. Contrariamente ao esperado, nenhuma das comparações intergrupos mostrou-se significantemente diferente na estória tigre-leão. Por outro lado, no que se refere aos artefatos, as duas últimas
Tabela 2. Comparações intergrupos para cada uma das estórias $(p=0,05)$

\begin{tabular}{lccc}
\hline \multirow{2}{*}{ Estória } & \multicolumn{3}{c}{ Idade } \\
\cline { 2 - 4 } & $\mathbf{6 - 8}$ & $\mathbf{6 - 1 0}$ & $\mathbf{8 - 1 0}$ \\
\hline Tigre - leão & n.s & n.s & n.s \\
Frango - peru & n.s & $p=0,011$ & n.s \\
Cavalo - zebra & n.s & $p=0,019$ & $p=0,002$ \\
Chumbo - ouro & n.s & $p=0,000$ & $p=0,000$ \\
Lixo - cadeira & n.s & n.s & n.s \\
Gravata - cadarço & n.s & n.s & n.s \\
\hline
\end{tabular}

estórias, tal como previsto, não foram constatadas diferenças significantes entre os grupos de idade.

Tais resultados estão graficamente representados na Figura 1. Conforme pode ser visualizado, os escores dos sujeitos nas estórias referentes a espécies naturais aumentam suavemente de 6 para 8 anos e mais acentuadamente de 8 para 10 anos, enquanto que, no tocante aos artefatos, os escores médios são praticamente iguais nos três grupos de idade.

\section{Discussão}

Os resultados deste trabalho estão bastante próximos dos encontrados por Keil (1989) em seu estudo original. Ressaltamos o termo próximo, uma vez que não houve concordância total. A análise dos dados mostra-nos que, no tocante às espécies naturais, ocorreram algumas divergências. Quais sejam: a não comprovação de diferenças estatisticamente significantes entre os grupos de idade em relação a uma das estórias (tigre - leão) e a inexistência de tais diferenças em todas as comparações intergrupos nas faixas etárias de 6 a 8 anos. Embora, em nosso entendimento, tais diferenças não comprometam crucialmente esta réplica do estudo original, nem ponham absolutamente em dúvida os achados de Keil, elas serão objeto de algumas considerações de nossa parte.

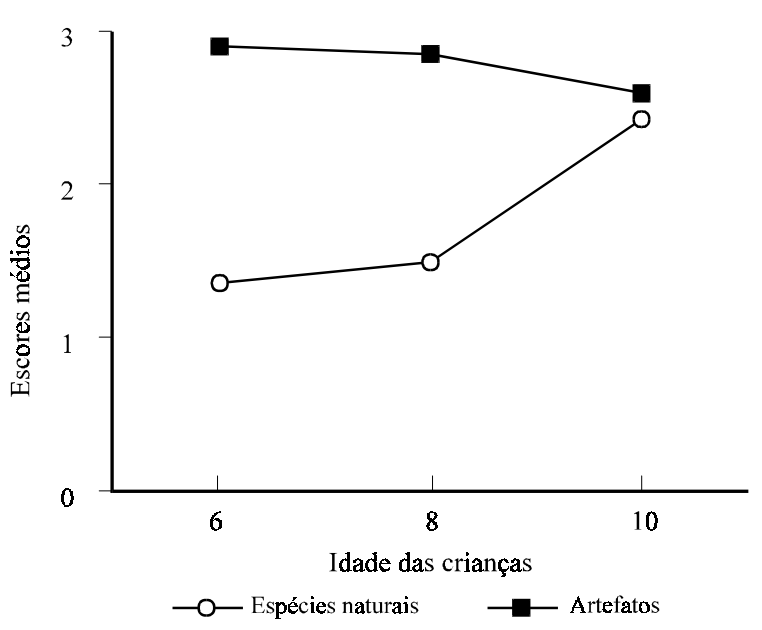

Figura 1. Escores médios dos sujeitos em função da idade e do tipo de estória 
No tocante à não comprovação de diferenças significantes entre os grupos de 6 e 8 anos, parece-nos razoável hipotetizar que as teorias das crianças de 8 anos ainda não se diferenciaram suficientemente das de 6 anos, de maneira tal a possibilitar a formação de grupos claramente distintos. É possível que o grupo de 8 anos tenha sido constituído por sujeitos que, ou não desenvolveram ainda teorias que contemplem os aspectos definidores da espécie ou que se encontravam numa fase de transição, oscilando entre os aspectos característicos e os definidores. Uma análise do tipo de respostas dos nossos sujeitos (ver Tabela1), revela que a primeira hipótese é a mais plausível, uma vez que, nas quatro estórias analisadas, o índice de escores 3 , indicativo de que o sujeito passou a levar em conta os aspectos definidores de um conceito, não ultrapassa a $30 \%$ das respostas avaliadas. Vale a pena, mais uma vez, ressaltar que este resultado em nada contraria os pressupostos teóricos desta visão de conceitos. Ele indica apenas que um pequeno grupo de sujeitos ainda não desenvolveu teorias adequadas neste domínio conceitual. É possível que isto tenha ocorrido pelo fato de as espécies naturais não terem sido trabalhadas de maneira conceitualmente adequada no contexto do ensino escolar freqüentado pelas crianças desta faixa etária, de modo a afetar significativamente suas concepções. Tal suposição nos faz sugerir que pesquisas posteriores sejam desenvolvidas no sentido de investigar as relações entre o ensino de conceitos e o desenvolvimento das teorias das crianças a respeito desta modalidade conceitual.

Um outro aspecto a ser explicado é a possível razão de não terem sido detectadas diferenças significantes entre os grupos na Estória 1. Um novo retorno à Tabela 1 mostra-nos que, embora as diferenças não tenham se revelado estatisticamente significantes, nossos dados revelam um progressivo aumento dos escores à medida que os sujeitos se tornam mais velhos. Assim sendo, ainda que as diferenças intergrupos não tenham atingido o nível de significância estatístico preestabelecido, a tendência dos dados aponta para o desenvolvimento de teorias mais maduras por parte das crianças, tal como previsto pela visão teórica.

Já no que se refere aos conceitos de artefatos, nossos resultados concordam inteiramente com os obtidos por Keil (1989). De maneira muito convincente, os dados deste estudo indicam que, mesmo crianças muito novas, não se deixam enganar pelos aspectos superficiais e avaliam com bastante correção a identidade dos artefatos, conseguindo identificar o que é superficial ou circunstancial e o que é definidor ou essencial nos artefatos. As transformações efetuadas nos objetos levam-nos a adquirir uma nova função e é esta função o atributo a ser considerado quando da decisão sobre se o objeto permanece o mesmo ou foi realmente transformado em outro artefato.

Em suma, ainda que nossos resultados não coincidam inteiramente com os encontrados nos estudos de Keil (1989), eles corroboram fortemente suas principais conclusões a respeito do desenvolvimento conceitual. Quais sejam: a) o desenvolvimento de teorias por parte de crianças, que as levam inicialmente a basear seus julgamentos em aspectos caracte- rísticos ou superficiais e sua substituição por teorias mais realistas, baseando seus julgamentos unicamente em atributos definidores e desconsiderando os aspectos característi$\cos$, não obstante sua saliência perceptiva e mesmo a frequiência com que ocorrem associados aos exemplos de conceitos; b) a não ocorrência simultânea dessas teorias para todos os domínios conceituais, mas seu aparecimento em momentos diferentes do desenvolvimento cognitivo. Como verificado neste estudo, teorias mais maduras relativas a artefatos desenvolvem-se antes do que as referentes às espécies naturais.

Em função dos nossos resultados acreditamos poder afirmar a adequação da visão teórica como um modelo explicativo do processo de desenvolvimento conceitual. Todavia, não se pode deixar de levar em conta que a teoria em apreço é ainda bastante nova em termos de ciência. Como vimos, ela foi originalmente proposta na década de 80 e, desde então, não foram muitos os trabalhos de pesquisa destinados a validá-la empiricamente. Assim sendo, esperamos que o presente trabalho possa contribuir para ajudar a avaliar a importância teórica da visão teórica na explicação do processo de formação de conceitos.

\section{Referências}

Bruner, J.S.; Goodnow, J.J.; Austin, G.A. (1967) A study of thinking. New York, Wiley. (Publicado originalmente em 1956).

Carey, S. (1985). Conceptual change in childhood. Cambridge, MA, MIT Press.

Keil, F.C. (1989) Concepts, kinds, and cognitive development. Cambridge, MA, MIT Press.

Lomônaco, J.F.B.; Caon, C.M.; Heuri, A.L.P.V.; Santos, D.M.M.; Franco, G.T. (1996) Do característico ao definidor: um estudo exploratório sobre o desenvolvimento de conceitos. Psicologia: Teoria e Pesquisa, 12, 51-60.

Lomônaco, J.F.B. (1997) A natureza dos conceitos: visões psicológicas. Tese de Livre-docência. Instituto de Psicologia da Universidade de São Paulo, São Paulo.

Lomônaco, J.F.B.; Capovilla, A.G.S.; Costa, C.E., Albernaz, J. M.; Souza, M.A. e Aguiar, R.M. (no prelo). Desenvolvimento dos conceitos: o paradigma das descobertas. Revista de Psicologia Escolar e Educacional.

Murphy, G.L.; Medin, D.L. (1985) The role of theories in conceptual coherence. Psychological Review, 92, 289-316.

Oliveira, M.B. (1994) Rumo a uma teoria dialética de conceitos. Em Abrantes, P.(Org.), Epistemologia e cognição. (pp. 25-69) Brasília, Editora da Universidade de Brasília.

Vygotsky L.S. (1979) Pensamento e linguagem. (M. Rezende, Trad.). Lisboa, Antídoto. (Trabalho original publicado em 1934). 


\section{Anexo 1:}

\section{Estórias Utilizadas nas Entrevistas com as Crianças:}

1) Tigre / Leão: Os cientistas pegaram um tigre como esse (mostra-se o desenho de um tigre). Eles usaram um alvejante especial para peles, removeram as listas e costuraram uma enorme juba, de tal modo que ele ficou assim (mostra-se o desenho de um leão). Depois da operação, o animal é um tigre ou um leão?

2) Frango / Peru: Criadores de aves pegaram um frango como esse (mostra-se o desenho de um frango) e colocaram nele enormes penas nas costas. Depois tiraram a crista da cabeça e do bico e colocaram uma outra bem maior embaixo do pescoço. Treinaram, então, o animal para fazer "glu-glu". Quando terminaram, esse animal parecia-se com essa figura (mostra-se a figura de um peru). Afinal, que animal os criadores tinham, um frango ou um peru?

3) Cavalo / Zebra: Veterinários de um zoológico pegaram um cavalo como esse (mostra-se a figura de um cavalo) e pintaram listas pretas e brancas no corpo dele. Depois cortaram sua crina e trançaram sua cauda. Então treinaram o animal para deixar de relinchar como um cavalo e o ensinaram a viver nas selvas da África, ao invés de viver no pasto. No final, que animal era esse, um cavalo ou uma zebra?

4) Chumbo / Ouro: Cientistas pegaram uma barra de chumbo como essa (mostra-se a figura de uma barra de chumbo), derreteram e misturaram uma tinta dourada brilhante. Então colocaram o líquido derretido numa forma e fizeram uma barra como essa (mostra-se a figura de uma barra de ouro). Quando eles terminaram, a barra que eles tinham era de chumbo ou de ouro?

5) Lata de lixo / Cadeira: Cientistas pegaram uma lata de lixo como essa (mostra-se a figura de uma lata de lixo). Eles pegaram a borda de cima e a cortaram em quatro tiras, fazendo com que essas tiras ficassem retas. Então eles cortaram o fundo da lata e pregaram nelas as quatro tiras. Depois eles cortaram um retângulo da parte do lado da lata de lixo e mais duas tiras. Aí eles juntaram todas essas partes assim (mostra-se a figura de uma cadeira com braços). Depois que eles acabaram, eles ficaram com uma lata de lixo ou com uma cadeira?

6) Gravata / Cordões de sapato: Costureiras pegaram uma gravata como essa (mostra-se a figura de uma gravata), cortaram em tiras finas, colocando pequenos tubinhos plásticos em suas pontas. Uma das tiras ficou parecida com essa figura (mostra-se a figura de um cadarço de sapato). Após terminar o serviço, o que as costureiras possuíam, gravatas ou cordões de sapatos? 